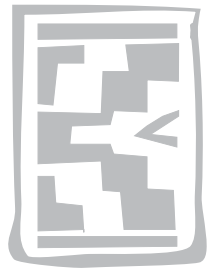

\title{
Ultrastructural features of the uterus in the sexually immature ostrich (Struthio camelus) during periods of ovarian inactivity and activity
}

\author{
M-C. MADEKUROZWA* \\ Department of Anatomy and Physiology, Faculty of Veterinary Science, University of Pretoria \\ Onderstepoort, 0110 South Africa
}

\begin{abstract}
MADEKUROZWA, M-C. 2007. Ultrastructural features of the uterus in the sexually immature ostrich (Struthio camelus) during periods of ovarian inactivity and activity. Onderstepoort Journal of Veterinary Research, 74:209-216

The ultrastructure of the surface epithelium and tubular glands of the uterus in the immature ostrich is described. In ostriches with inactive ovaries the uterus is lined by a non-ciliated simple columnar epithelium, with basally located heterochromatic nuclei. Scanning electron microscopy revealed that these non-ciliated cells have a dense microvillous cover. A simple columnar to pseudostratified columnar epithelium, comprised of non-ciliated and ciliated cells, lines the uterus in birds with active ovaries. The ciliated cells possess a wide luminal region, which contains a nucleus and various organelles. An accumulation of secretory granules was observed in the apical regions of the non-ciliated cells, as well as in a few ciliated cells. In addition to non-ciliated and ciliated cells, a cell type with rarefied cytoplasm was also identified. These cells appear to correspond to calcium secreting cells identified in other avian species.

The results of this study indicate that, although uterine differentiation is present in immature ostriches with active ovaries, the production of secretory product appears to occur mainly in non-ciliated epithelial cells.
\end{abstract}

Keywords: Electron microscopy, ostrich, uterus, ultrastructure

\section{INTRODUCTION}

Although a low latitude inhabitant, the mature ostrich (Struthio camelus) is a seasonal breeder, with reproductive activity being influenced by photoperiod and probably feed availability (Sauer 1972; Degen, Weil, Rosenstrauch, Kam \& Dawson 1994; Hicks-Alldredge 1998). Likewise, studies on the immature ostrich have revealed a seasonality in the differentiation of the reproductive systems of both male and female birds (Madekurozwa 2002a, b, 2004, 2005; Madeku-

\footnotetext{
* E-mail: madex@op.up.ac.za
} Accepted for publication 13 March 2007-Editor rozwa, Chabvepi, Matema \& Teerds 2002). In one particular study changes in the morphology of the uterine region of the oviduct were found in immature ostriches having either active or inactive ovaries (Madekurozwa 2004). However, despite the information gained from this study, our knowledge of the seasonal morphological changes in the uterus is incomplete as there do not appear to have been any ultrastructural studies carried out on this oviducal region in the immature ostrich. In addition, it would appear from the literature that ultrastructural investigations of the uterus in avian species have concentrated on mature birds during the breeding season (Breen \& De Bruyn 1969; Wyburn, Johnston, Draper \& Davidson 1973; Bakst \& Howarth 1974; Bakst 1978). 
In light of the paucity of ultrastructural information on the uterus of immature birds, and of the immature ostrich in particular, the present study was undertaken. The ultrastructural changes occurring in the surface epithelium and tubular glands of the uterus in the immature ostrich during ovarian inactivity and activity are described.

\section{MATERIALS AND METHODS}

Forty sexually immature female ostriches aged between 12 and 14 months and weighing 90-100 kg, were used. Twenty-five of the birds had active ovaries, which contained 10-25 small, predominantly yellow-yolk follicles, with the diameters of the largest follicles ranging from 11 to $19 \mathrm{~mm}$. These birds were sampled between September and December, a period of increasing daylength in the southern hemisphere. Fifteen ostriches with inactive ovaries were collected from March to June, a period of decreasing daylength. The birds were killed at a commercial abattoir, employing a standard slaughter protocol.

Oviducts were collected $10-15$ min after the birds were killed.

For transmission and scanning electron microscopy tissue samples from the major part of the uterus were fixed by immersion in $3 \%$ glutaraldehyde buffered in $0.067 \mathrm{M}$ sodium cacodylate buffer ( $\mathrm{pH} 7.2)$. After fixation the tissue samples for transmission electron microscopy were dehydrated through a graded series of ethanol and embedded in an epoxy resin. Semi-thin sections were stained with toluidine blue, while ultra-thin sections were stained with uranyl acetate and lead citrate. The samples were viewed with a Philips CMIO transmission electron microscope (FEl, Eindhoven, The Netherlands).

Tissue samples for scanning electron microscopy were dehydrated through a graded series of acetone and thereafter dried in a critical point dryer. The tissues were then mounted on aluminium stubs and coated with gold palladium before they were viewed in a Philips XL20 scanning electron microscope (FEI, Eindhoven, The Netherlands).

Additional samples for light microscopy were immersion-fixed in Bouin's fluid for $12 \mathrm{~h}$. After fixation, tissues were processed routinely for histology and embedded in paraffin wax. The presence of acid and neutral mucopolysaccharides was demonstrated using a combined alcian blue-periodic acid Schiff (PAS) technique (Mowry 1956).

\section{RESULTS}

\section{Immature ostriches with inactive ovaries}

Scanning electron microscopy (SEM) revealed the presence of a series of uniform undulating primary mucosal folds, which were separated by deep crypts. Non-ciliated, microvillous cells lined the surface of the uterus in these birds (Fig. 1). The microvillous cover was generally dense, although occasional cells with only a few microvilli were also observed.

Transmission electron microscopy showed that the non-ciliated cells formed a simple columnar epithelium. The cells contained basally located, large heterochromatic nuclei. Most of the organelles, which included mitochondria, electron dense bodies, rough endoplasmic reticulum (RER) and ribosomes, were located in the supranuclear area of the cell (Fig. 2). The electron dense bodies varied in shape and heterogenicity. A series of junctional complexes linked the apical regions of adjacent cells. In addition, the lateral plasma membranes displayed simple folding, both apically and basally.

In birds with inactive ovaries the uterine epithelium did not stain with alcian blue or PAS.

\section{Immature ostriches with active ovaries}

The mucosa of the uterus was thrown into thick lamellar primary folds, which still retained the arrangement observed in birds with inactive ovaries. Deep crypts indented the primary folds, resulting in the formation of numerous secondary folds (Fig. 3). Ciliated and non-ciliated cells, with the former being predominant, lined the mucosal folds. Tufts of cilia completely covered adjacent non-ciliated cells in most areas. However, in areas lined by only a few ciliated cells, the non-ciliated cells and the openings of tubular glands were clearly visible (Fig. 4). The glandular openings were circumscribed by a raised area, which possessed a few microvilli (Fig. 4).

Transmission electron microscopy revealed that in birds with active ovaries a simple columnar to pseudostratified columnar epithelium lined the uterus. Non-ciliated cells formed the simple columnar epithelium, while the pseudostratified epithelium consisted of both non-ciliated and ciliated cells.

The ciliated cells exhibited well-developed, regularly arranged cilia, which were intermingled with microvilli. The elongated or irregular shaped, euchromatic nuclei, were located in the wide luminal regions of the cells (Fig. 5). Several mitochondria, RER profiles, electron dense bodies and bundles of fibrils 

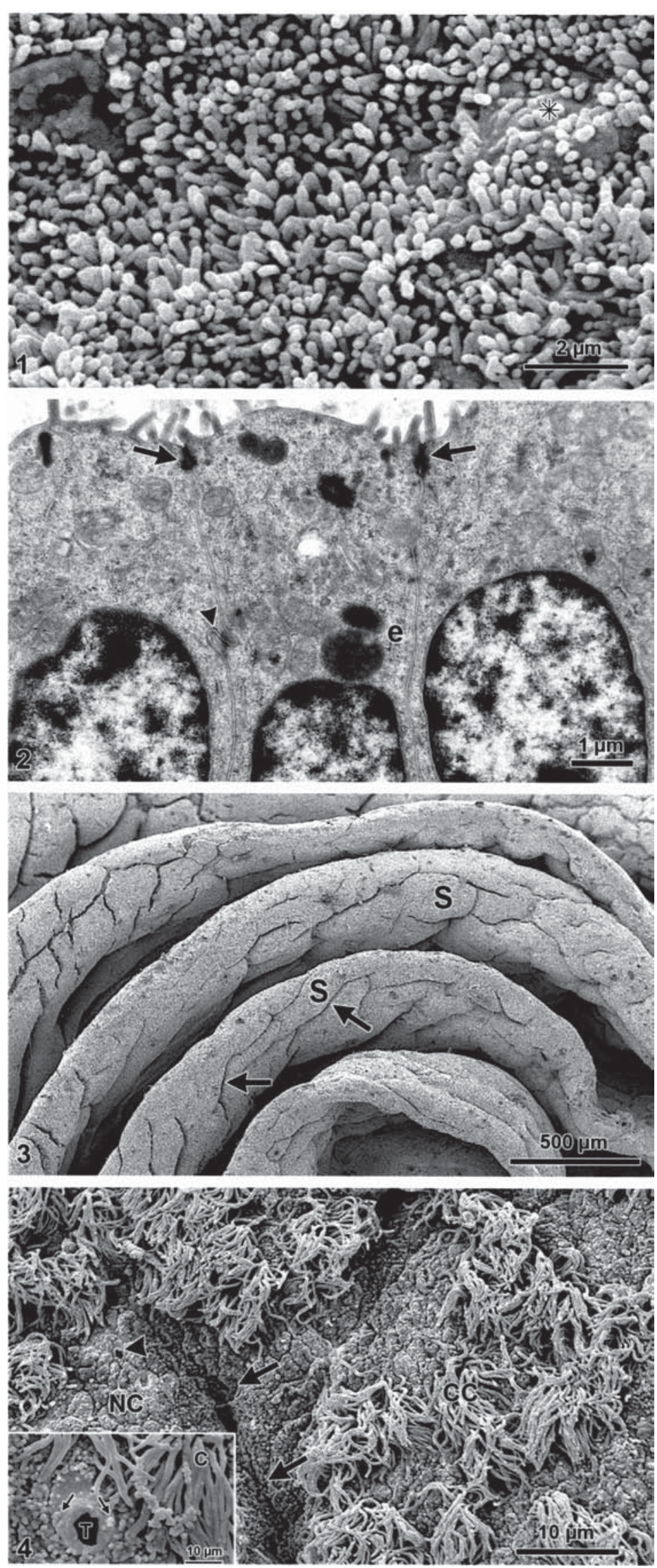

FIG. 1 Scanning electron micrograph of non-ciliated microvillous cells in the uterus of an immature ostrich with an inactive ovary. Some cells (asterisk) have a sparse covering of microvilli

FIG. 2 Transmission electron micrograph of the non-ciliated simple columnar epithelium in an immature ostrich with an inactive ovary. Most of the organelles which include electron dense bodies (e) are concentrated in the supranuclear cytoplasm. Junctional complexes (arrows) and folding (arrowhead) of the lateral plasma membranes unite adjacent cells

FIG. 3 Scanning electron micrograph of undulating mucosal folds in the uterus of an immature ostrich with an active ovary. The primary mucosal folds are further divided into secondary folds (S) by crypts (arrows)

FIG. 4 Scanning electron micrograph showing non-ciliated (NC) and ciliated (CC) cells in the uterus of an immature ostrich with an active ovary. The mucosal surface is indented with crypts (arrows) resulting in the formation of secondary folds. In addition, occasional tubular gland openings are observed (arrowhead). Inset: Scanning electron micrograph of a tubular gland opening (T) in the uterus of an immature ostrich with an active ovary. The raised rim of the tubular gland opening possesses a few microvilli (arrows). C: tuft of cilia 

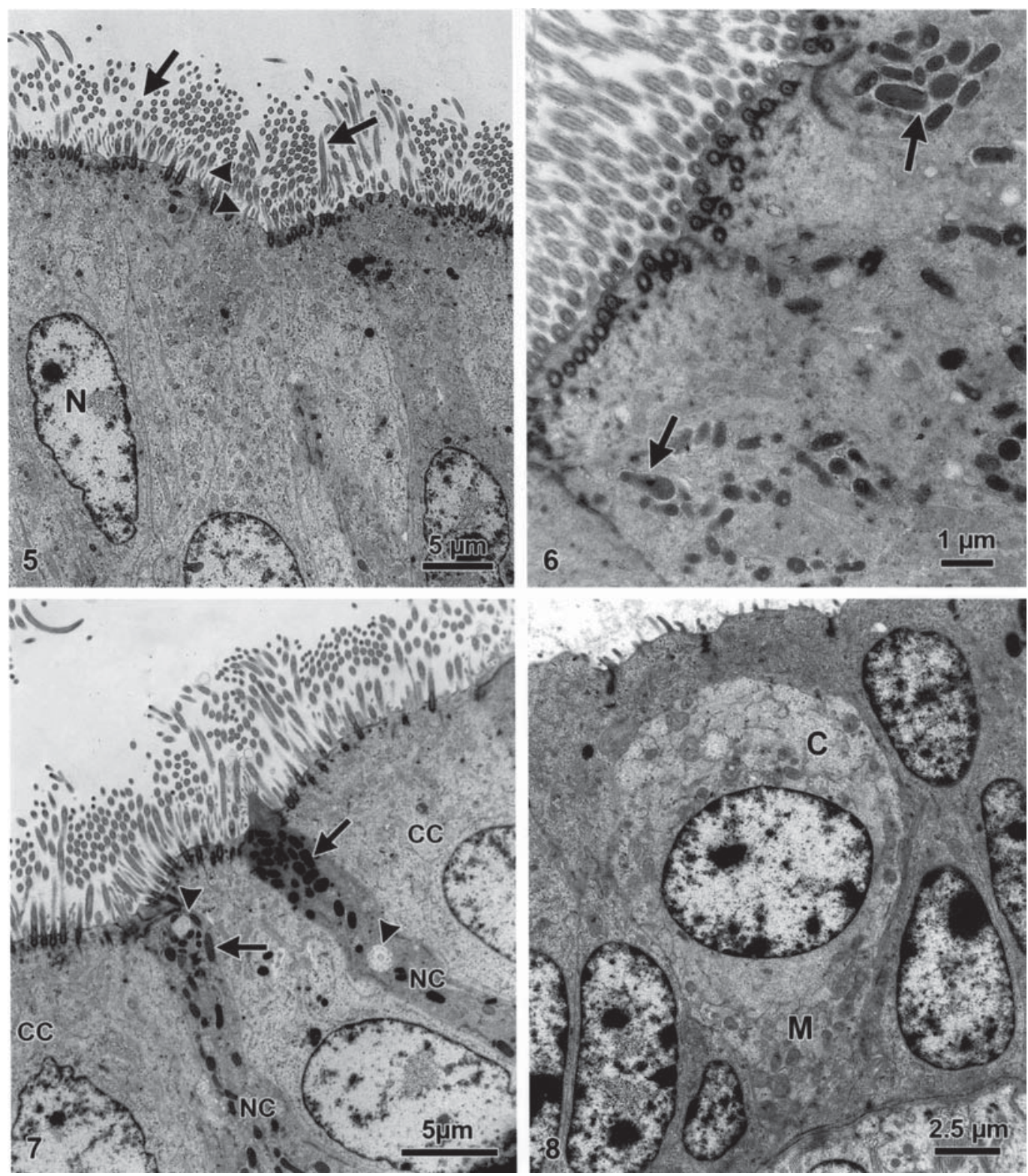

FIG. 5 Survey transmission electron micrograph of the pseudostratified columnar epithelium lining the uterus in an immature ostrich with an active ovary. Ciliated cells typically contain elongated or irregular shaped nuclei (N). The apical plasma membrane exhibits cilia (arrows) and microvilli (arrowheads)

FIG. 6 Transmission electron micrograph showing the occurrence of secretory granules (arrows) in ciliated cells in the uterus of an immature ostrich with an active ovary

FIG. 7 Survey transmission electron micrograph of the pseudostratified columnar epithelium lining the uterus in an immature ostrich with an active ovary. Slender non-ciliated cells (NC) alternate with ciliated cells (CC). The non-ciliated cells contain secretory granules (arrows). Vacuoles (arrowheads) occur either in the middle or apical regions of the non-ciliated cells

FIG. 8 Transmission electron micrograph of the pseudostratified columnar epithelium lining the uterus in an immature ostrich with an active ovary. A few cells with electron lucent cytoplasm (C) and a basal accumulation of mitochondria (M) occur in the surface epithelium

were identified in the supranuclear cytoplasm. Secretory granules occurred in the supranuclear regions of a few cells (Fig. 6).
In some areas slender non-ciliated cells were observed between the ciliated cells. The nuclei of the non-ciliated cells were elongated, heterochromatic 

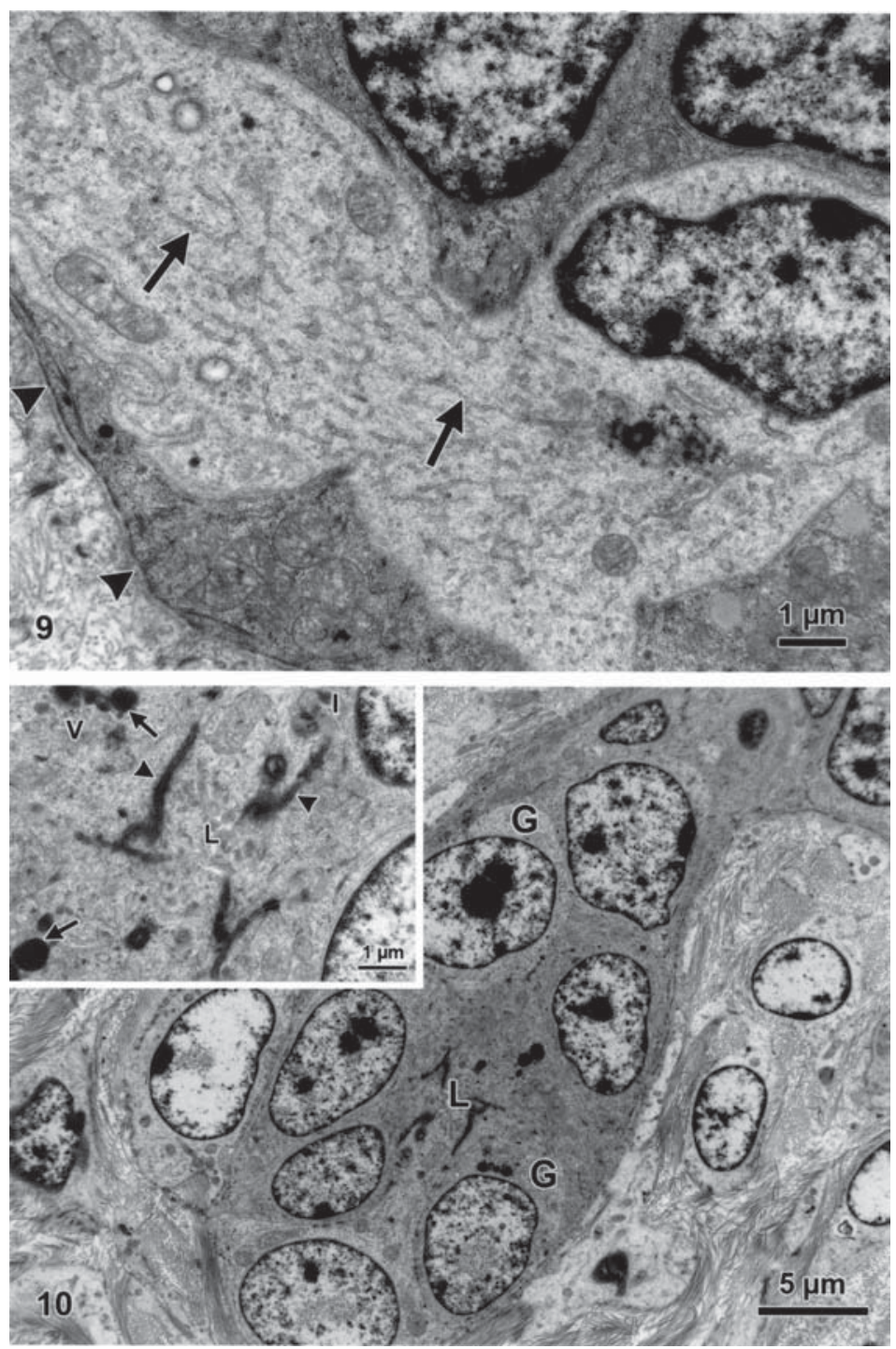

FIG. 9 Transmission electron micrograph of an electron lucent cell located in the basal region of the epithelium. RER profiles (arrows) are a prominent feature of these cells. Arrowheads: basal lamina

FIG. 10 Survey transmission electron micrograph of a tubular gland in the uterus of an immature ostrich with an active ovary. G: gland cells. L: lumen. Inset: The luminal regions of the gland cells contain several electron dense bodies (arrows) and accumulations of vesicles (v). Intricate folding (I) of the plasma membrane and junctional complexes (arrowheads) unite adjacent gland cells. L: lumen

and basally placed. Secretory granules were concentrated mainly in the apical regions of the cells (Fig. 7). Other organelles and inclusions present in the supranuclear cytoplasm included mitochondria, profiles of RER and vesicles. Vacuoles containing membranous profiles were observed in either the middle or apical regions of the non-ciliated cells. In both non-ciliated and ciliated cells folding of the lateral plasma membrane, in the apical parts of the cells, was present although not extensive. Wellformed junctional complexes were observed apically, as well as distally along the lateral plasma membrane.

Occasional cells with rarefied cytoplasm were observed in the epithelium. The location of these electron lucent cells varied, with cells being observed in both the apical and basal regions of the epithelium. The apical electron lucent cells had a wide luminal region, which contained a round nucleus with peripheral clumps of heterochromatin. An accumulation of mitochondria was observed in the narrow basal region of the cell (Fig. 8). A second type of electron lucent cell was observed close to the basal lamina. These cells contained irregular shaped heterochromatic nuclei. Profiles of RER, mitochondria and vacuoles were observed in the cytoplasm, which contained relatively few organelles (Fig. 9). In addition to the electron lucent cells, a few cells with condensed cytoplasm and heterochromatic, elongated nuclei were also observed in the epithelium. Apically placed electron dense bodies were the only recognizable organelles in these cells.

Groups of pyramidal shaped cells, which displayed numerous microvilli on their luminal surfaces, formed the tubular glands (Fig. 10). The lumina of the glands were devoid of secretory material. Heterochromatic 
nuclei, which were either round or elongated in shape, were placed centrally or basally in the cells. Distributed in the supranuclear cytoplasm were mitochondria, vesicles, microfilaments and profiles of RER. The presence of a few lipid droplets and electron dense bodies of various sizes was noted in some cells. Well-developed junctional complexes and folding of the lateral plasma membranes characterized the apical regions of the gland cells (Fig. 10).

The majority of non-ciliated surface epithelium cells stained strongly with alcian blue and PAS, indicating the presence of both acidic and neutral mucopolysaccharides. Tubular gland cells and the majority of ciliated cells were negative for both alcian blue and PAS. Occasional ciliated cells displayed supranuclear diastase-resistant PAS staining, which indicated the presence of neutral mucopolysaccharides.

\section{DISCUSSION}

The present study has established that the uterus in the immature ostrich undergoes ciliogenesis and gland formation, which appear to be associated with the presence of an active ovary. Although hormonal studies on the immature ostrich have not been carried out, based on the results of the present and previous studies (Madekurozwa 2002a, b, 2004, 2005), it would appear that the ovarian follicles in birds with active ovaries produce hormones in sufficient quantities to stimulate oviducal differentiation. These oviducal changes are most likely stimulated by oestrogen, as it is known that in birds small yellow-yolk follicles produce oestrogen whilst preovulatory follicles secrete progesterone (Tilly, Kowalski \& Johnson 1991). Furthermore, research in both birds (Wrenn 1971; Anderson \& Hein 1976; Perche, Laine, Pageaux, Laugier \& Sandoz 1989) and mammals (Sawyer, Olson \& Gorell 1984; Verhage, Mavrogianis, Boice, Li \& Fazleabas 1990; Abe \& Oikawa 1993) has indicated that the stimulation of ciliogenesis and tubular gland development is primarily a function of oestrogen.

As revealed by SEM, ciliogenesis in the uterus of immature ostriches with active ovaries was patchy. Similar observations were also made in the magnum of immature ostriches (Madekurozwa 2005). To date there is no published information on the distribution of ciliated cells in the uterus of the mature ostrich. As a result it is impossible to determine whether the uneven distribution of ciliated cells observed in the current study is a common observa- tion in the ostrich or if it is peculiar to immature ostriches.

Transmission electron microscopic observations of both non-ciliated and ciliated cells in the uterus of the immature ostrich with an active ovary showed that the morphology of these cells is similar to cells in the uterus of the domestic fowl (Johnston, Aitken \& Wyburn 1963), Pekin duck (Balachandran, Bhatnagar \& Geissinger 1985), Japanese quail (Yamamoto, Ozawa \& Nagai 1985) and mature ostrich (Muwazi, Baranga, Kayanja \& Schliemann 1982). An interesting observation of the present study was the occurrence of secretory granules in the majority of non-ciliated cells, but only in a few ciliated cells. Based on the alcian blue-PAS staining reaction, the non-ciliated cells contained a mixture of acid and neutral mucopolysaccharides, while ciliated cells only demonstrated the latter mucopolysaccharide. Although the exact nature of these mucopolysaccharides in the immature ostrich is unknown, it is known that non-ciliated cells in the uterus of the domestic fowl produce the proteoglycan, ovoglycan, which is a component of the eggshell matrix (Fernandez, Moya, Lopez \& Arias 2001). In addition, the non-ciliated cells in the domestic fowl also produce osteopontin, a matrix protein involved in the mineralization of the eggshell (Fernandez, Escobar, Lavelin, Pines \& Arias 2003). The cuticle and shell pigment are thought to be produced by both ciliated and non-ciliated cells (Breen \& De Bruyn 1969; Baird, Solomon \& Tedstone 1975).

In addition to typical non-ciliated and ciliated epithelial cells, cells with either rarefied or condensed cytoplasm were also observed. Cells with rarefied cytoplasm have been identified in the uterine region of the mature ostrich (Muwazi et al. 1982), as well as in the domestic fowl (Ljungkvist 1967). Ljungkvist (1967) identified the electron lucent cells as unicellular calcium secreting glands. Further research by Solomon, Fryer \& Baird (1975) identified the surface epithelium of the uterus as the primary site of calcium secretion, although the exact cells involved were not demonstrated.

In addition to the electron lucent cells, a few cells with condensed cytoplasm were observed in the uterine epithelium of the immature ostrich. Based on the morphological features displayed it is likely that these cells were degenerating. To date no detailed ultrastructural studies have been conducted on the regression of the oviducal epithelium in birds. Light microscopic studies conducted on the Japanese quail (Eroschenko \& Wilson 1974) and the 
pied myna (Gupta \& Maiti 1987) indicate that large sections of the oviducal epithelium slough off during regression. Further ultrastructural studies need to be carried out on immature ostriches with regressive oviducts to ascertain the mode and stages of involution in this species.

In addition to the surface epithelium, tubular glands located in the lamina propria also make a significant contribution to the secretions of the uterus. In this study SEM revealed the presence of several tubular gland openings in the uterus of birds with active ovaries. In the magnum of the immature ostrich the glandular openings took the form of pores surrounded by non-ciliated cells (Madekurozwa 2005). The raised rim, which surrounded the glandular openings in the uterus of the immature ostrich, was not observed in the magnal region. Although Bakst \& Howarth (1974) observed glandular openings in the magnum of the domestic hen, no mention of these structures was made in the description on the uterus. This might have been due to the presence of numerous cilia, which effectively obscured the gland openings.

The ultrastructural morphology of the tubular gland cells in the uterus of the immature ostrich is similar to that of the Japanese quail (Yamamoto et al. 1985) and the domestic fowl (Breen \& De Bruyn 1969). As in the Japanese quail (Yamamoto et al. 1985) and domestic fowl (Breen \& De Bruyn 1969) the gland cells in the immature ostrich were devoid of secretory granules. Research conducted by Jande, Tolnai \& Lawson (1981) and Yamamoto et al. (1985) has shown that gland cells are involved in the transportation of calcium, which is utilized in the calcification of the eggshell. Furthermore, Wasserman, Smith, Smith, Brindak, Fullmer, Krook, Penniston \& Kumar (1991) have localized a calcium pump in the microvillar plasma membrane of gland cells and the calcium binding protein, calbindin- $\mathrm{D}_{28 \mathrm{k}}$, in the cytoplasm of the gland cells. These findings suggest that the tubular glands are the primary sites of calcium secretion in the uterus. However, as mentioned previously, cells in the surface epithelium are also thought to play a role in calcium secretion (Ljungkvist 1967; Solomon et al. 1975).

In conclusion, the present ultrastructural study has shown cellular differentiation in the form of ciliated cells and tubular glands in the uterus of immature ostriches with active ovaries. A significant finding is the presence of secretory granules in most non-ciliated cells. However, the presence of secretory granules in only a few of the ciliated cells indicates that the secretory cells in the uterus of the immature ostrich are not fully functional.

\section{ACKNOWLEDGEMENTS}

The author thanks technical staff in the University of Pretoria's Department of Pathology, Electron Microscope Unit and Department of Education Innovation (Creative Studios) for their assistance. The University of Pretoria and the National Research Foundation (Thuthuka programme) funded this study.

\section{REFERENCES}

ABE, H. \& OIKAWA, T. 1993. Observations by scanning electron microscopy of oviductal epithelial cells from cows at follicular and luteal phases. Anatomical Record, 235:399-410.

ANDERSON, R.G.W. \& HEIN, C.E. 1976. Estrogen dependent ciliogenesis in the chick oviduct. Cell and Tissue Research, 171:459-466.

BAIRD, T., SOLOMON, S.E. \& TEDSTONE, D.R. 1975. Localisation and characterization of egg shell porphyrins in several avian species. British Poultry Science, 16:201-208.

BAKST, M. 1978. Scanning electron microscopy of the oviducal mucosa apposing the hen ovum. Poultry Science, 57:10651069.

BAKST, M. \& HOWARTH, B. 1974. SEM preparation and observations of the hen's oviduct. Anatomical Record, 181:211226.

BALACHANDRAN, A., BHATNAGAR, M.K. \& GEISSINGER, H.D. 1985. Scanning and transmission electron microscopic studies on the oviducts of Pekin ducks fed methyl mercury containing diets. Scanning Electron Microscopy, 1:311-322.

BREEN, P.C. \& DE BRUYN, P.P.H. 1969. The fine structure of the secretory cells of the uterus (shell gland) of the chicken. Journal of Morphology, 128:35-66.

DEGEN, A.A., WEIL, S., ROSENSTRAUCH, A., KAM, M. \& DAWSON, A. 1994. Seasonal plasma levels of luteinizing and steroid hormones in male and female domestic ostriches (Struthio camelus). General and Comparative Endocrinology, 93:21-27.

EROSCHENKO, V.P. \& WILSON, W.O. 1974. Histological changes in the regressing reproductive organs of sexually mature male and female Japanese quail. Biology of Reproduction, 11:168-179.

FERNANDEZ, M.S., MOYA, A., LOPEZ, L. \& ARIAS, J.L. 2001. Secretion pattern, ultrastructural localization and function of extracellular matrix molecules involved in eggshell formation. Matrix Biology, 19:793-803.

FERNANDEZ, M.S., ESCOBAR, C., LAVELIN, I., PINES, M. \& ARIAS, J.L. 2003. Localization of osteopontin in oviduct tissue and eggshell during different stages of the avian egg laying cycle. Journal of Structural Biology, 143:171-180.

GUPTA, S.K. \& MAITI, B.R. 1987. Seasonal changes in the oviduct of the pied myna (Aves: Sturnidae). Journal of Morphology, 194:247-263.

HICKS-ALLDREDGE, K. 1998. Ratite reproduction. Veterinary Clinics of North America. Food Animal Practice, 14:437453. 
JANDE, S.S., TOLNAI, S. \& LAWSON, D.E.M. 1981. Immunohistochemical localization of vitamin D-dependent calciumbinding protein in duodenum, kidney, uterus and cerebellum of chickens. Histochemistry, 71:99-116.

JOHNSTON, H.S., AITKEN, R.N.C. \& WYBURN, G.M. 1963. The fine structure of the uterus of the domestic fowl. Journal of Anatomy, 97:333-344.

LJUNGKVIST, H.I. 1967. Light and electron microscopic study of the effect of oestrogen on the chicken oviduct. Acta Endocrinologica, 56:391-402.

MADEKUROZWA, M.-C. 2002a. A study of the immunohistochemical localization of the progesterone and oestrogen receptors in the magnum of the immature ostrich, Struthio camelus. Anatomica Histologica Embryologica, 31:317-320.

MADEKUROZWA, M.-C. 2002b. Progesterone and oestrogen receptor immunoreactivity in the vagina of the immature ostrich, Struthio camelus. British Poultry Science, 43:450-456.

MADEKUROZWA, M.-C., CHABVEPI, T.S., MATEMA, S. \& TEERDS, K.J. 2002. Relationship between seasonal changes in spermatogenesis in the juvenile ostrich (Struthio came-

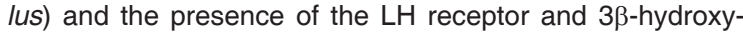
steroid dehydrogenase. Reproduction, 123:735-742.

MADEKUROZWA, M.-C. 2004. Immunohistochemical localization of progesterone and oestrogen receptors in the shell gland of sexually immature ostriches (Struthio camelus) with active or inactive ovaries. Research in Veterinary Science, 76:63-68.

MADEKUROZWA, M.-C. 2005. Morphological features of the luminal surface of the magnum in the sexually immature ostrich (Struthio camelus). Anatomica Histologica Embryologica, 34:350-353.

MOWRY, R.W. 1956. Observations on the use of sulphuric ether for the sulphation of hydroxyl groups in tissue sections. Journal of Histochemistry and Cytochemistry, 4: 407-409.

MUWAZI, R.T., BARANGA, J., KAYANJA, F.I.B. \& SCHLIEMANN, H. 1982. The oviduct of the ostrich Struthio camelus massaicus. Journal of Ornithology, 123:425-433.

PERCHE, O., LAINE, M.C., PAGEAUX, J.F., LAUGIER, C. \& SANDOZ, D. 1989. Modification of cell evagination and cell differentiation in quail oviduct hyperstimulated by progesterone. Biology of the Cell, 67:123-134.

SAUER, F.E.G. 1972. Aberrant sexual behaviour in the South African ostrich. The Auk, 89:717-737.

SAWYER, H.R., OLSON, P.N. \& GORELL, T.A. 1984. Effects of progesterone on the oviducal epithelium in estrogen-primed prepubertal beagles: light and electron microscopic observations. American Journal of Anatomy, 169:75-87.

SOLOMON, S.E., FRYER, J.R. \& BAIRD, T. 1975. The ultrastructural localization of calcium in the avian shell gland. Journal of Microscopy, 105:215-222.

TILLY, J.L., KOWALSKI, K.I. \& JOHNSON, A.L. 1991. Stage of ovarian follicular development associated with the initiation of steroidogenic competence in avian granulosa cells. Biology of Reproduction, 44:304-314.

VERHAGE, H.G., MAVROGIANIS, P.A., BOICE, M.L., LI, W. \& FAZLEABAS, A.T. 1990. Oviducal epithelium of the baboon: hormonal control and the immuno-gold localization of oviduct-specific glycoproteins. American Journal of Anatomy, 187:81-90.

WASSERMAN, R.H., SMITH, C.A., SMITH, C.M., BRINDAK, M. E., FULLMER, C.S., KROOK,

L, PENNISTON, J.T. \& KUMAR, R. 1991. Immunohistochemical localization of a calcium pump and calbindin- $\mathrm{D}_{28 \mathrm{k}}$ in the oviduct of the laying hen. Histochemistry, 96:413-418.

WRENN, J.T. 1971. An analysis of tubular gland morphogenesis in chick oviduct. Developmental Biology, 26:400-415.

WYBURN, G.M., JOHNSTON, H.S., DRAPER, M.H. \& DAVIDSON, M.F. 1973. The ultrastructure of the shell forming region of the oviduct and the development of the shell of Gallus domesticus. Quarterly Journal of Experimental Physiology, 58:143-151.

YAMAMOTO, T., OZAWA, H. \& NAGAI, H. 1985. Histochemical studies of Ca-ATP-ase, succinated and $\mathrm{NAD}^{+}$-dependent isocitrate dehydrogenases in the shell gland of laying Japanese quails: with special reference to calcium-transporting cells. Histochemistry, 83:221-226. 